\title{
Why We Shouldn't Swallow Worm Slices: A Case Study in Semantic Accommodation
}

Mark Moyer

\begin{abstract}
A radical metaphysical theory typically comes packaged with a semantic theory that reconciles those radical claims with common sense. The metaphysical theory says what things exist and what their natures are, while the semantic theory specifies, in terms of these things, how we are to interpret everyday language. Thus may we "think with the learned, and speak with the vulgar." This semantic accommodation of common sense, however, can end up undermining the very theory it is designed to protect. This paper is a case study, showing in detail how one popular version of temporal parts theory is self-undermining. This raises the specter that the problem generalizes to other metaphysical theories.

The traditional flavor of temporal parts theory, Worm Theory, claims that everyday objects are four-dimensional space-time worms. An alternative flavor, Slice Theory, claims that objects are not space-time worms but are instead momentary slices of these worms. The differences, we find, are not nearly as great as advertised. In fact, the differences in the two metaphysical theories are entirely masked by compensating differences in the accompanying semantic theories. As a result, the two theories generate exactly the same truth conditions. Common sense says that I was born years ago. Slice Theory adopts a semantic theory that accommodates such claims, but in doing so, it also endorses the claim that I, like other everyday objects, persist and thus do not exist for a mere moment. That is, the metaphysical claims constitutive of Slice Theory are denied by the very semantic theory Slice Theory adopts to accommodate common sense. Slice Theory thus undermines itself.
\end{abstract}




\section{Why We Shouldn't Swallow Worm Slices}

Metaphysicians make many claims that at least appear to fly in the face of common sense. "Only ideas exist!" "Only simples exist!" "Many objects occupy exactly the same place at a time!" Quite often, however, they accommodate common sense by means of a semantic theory according to which the claims of common sense, at least in the mouths of non-philosophers, are true. Such paraphrasing strategies have become ubiquitous. Thereby, it is hoped, we save the phenomena - we may "think with the learned, and speak with the vulgar." Semantic accommodation, however, threatens to undermine the metaphysical theory it is supposed to save. For while the semantic theory may save the claims of common sense, in so doing it endorses claims contradicting those claims that characterize the theory. What meaning can be given to a theory that claims that chairs don't exist if it simultaneously endorses the claim "there are chairs in the closet"? How are we to understand a theory that says that at least two objects, a piece of copper and a statue, are on the mantle if that theory says that the statement, "there is exactly one object on the mantle," is true?

In this paper I will not attempt the ambitious task of showing that every combination of a radical metaphysic together with an accommodating semantic theory undermines itself. I will, however, develop this sort of worry for one particular theory that has become increasingly popular. Stage thory, or 'Slice Theory', is a metaphysical theory about the nature of everyday objects conjoined with a semantic theory about our tensed predicates. Stage Theory, say I, is self-undermining. I hope to resolve this particular issue in material constitution but in so doing I also hope to give some evidence that the problem generalizes.

According to Worm Theory, objects have temporal parts much as they have spatial parts. ${ }^{2}$ Me from my right ankle upward to my right knee is a spatial part of me; me from my tenth birthday forward to my twentieth birthday is a temporal part of me. Thus, objects are fourdimensional time worms stretching through space and time. A spatially maximal momentary temporal part of a worm is a temporal slice, and ordinary objects are sums of temporal slices, each existing at a different time. A person is thus made up of person slices, a lake of lake slices, and the world of world slices. The requirements for being an object of kind $\mathrm{K}$ can be broken into two: those (synchronic) conditions specifying what is required at each moment to be a $\mathrm{K}$, and those (diachronic) conditions specifying what is required over time to be a $\mathrm{K}$. Or, as the Worm Theorist would say, there are requirements for being a ' $\mathrm{K}$ slice', and there is the $\mathrm{I}_{\mathrm{K}}$ - relation that all $\mathrm{K}$ slices must bear to each other to compose a K. Finally, an object is bent, tall, etc. at $\mathrm{t}$ in virtue of having a temporal slice existing at $\mathrm{t}$ that is bent, tall, etc.

Slice Theory, often called Stage Theory, endorses the existence of the same temporal parts, agreeing that there are person slices, lake slices, and world slices, and that there are worms made up of these slices. ${ }^{3}$ Slice Theory also employs the same notion of a $\mathrm{K}$ slice and of the $\mathrm{I}_{\mathrm{K}^{-}}$ relation that all $\mathrm{K}$ slices belonging to a $\mathrm{K}$ worm bear to each other. Slice Theory differs,

\footnotetext{
${ }^{1}$ Berkeley, Of the Principles of Human Knowledge, Part I, principle 51 (many note that Berkeley is perhaps paraphrasing Bacon's De Augmentis Scientiarum).

${ }^{2}$ See, e.g., Lewis, "Survival and Identity," pp. 17-40; Heller, "Temporal Parts of Four Dimensional Objects".

${ }^{3}$ See Sider, Four-Dimensionalism, §5.8; Katherine Hawley, How Things Persist, esp. ch. 2; Sider, "All the World's a Stage," 433-453; Perry, "Can the Self Divide?" pp. 463-488 (Perry considers but does not endorse the view that objects are time slices); and Armstrong, "Reply to Lewis," p.41.
} 
however, in saying that ordinary objects are not the worms composed of $\mathrm{I}_{\mathrm{K}}$-related slices but rather the slices themselves.

An analogy should help. Just as Lewis claims that people and objects are restricted to a single world, so Slice Theory claims that people and objects are restricted to a single time. ${ }^{4}$ According to Lewis, statements about what is possible or necessary for some object are true in virtue of modal counterpart relations that that world-bound object bears to objects at other worlds. Likewise, according to Slice Theory statements about what will or did happen to some object are true in virtue of temporal counterpart relations that that time-bound object (i.e., the slice) has to objects (i.e., slices) at other times. Thus, while slices occupy only a single time, we can speak of the future or past of objects that are those slices, all in virtue of counterpart relations invoked by talk of objects of that kind.

The contrast should become clearer by comparing the semantics of tensed statements for Worm Theory and Slice Theory. As a toy example, we'll consider a simple past tense sentence. According to Worm Theory,

"Tom was tall" is true at t iff 'Tom' refers to a time worm w, and some slice of w prior to $\mathrm{t}$ is tall.

According to both Sider and Hawley, the leading exponents of Slice Theory, an utterance of 'Tom' refers to the slice, at the time of utterance, of the time worm associated by the utterer with the name 'Tom'.5 Call this slice s. Slice Theory then sets out rather different truth conditions:

"Tom was tall" is true at $\mathrm{t}$ iff some slice prior to $\mathrm{t}$ is I-related to $\mathrm{s}$ and is tall.

In both cases the object language contains tensed predications while the metalanguage contains only tenseless predications.

Through the use of temporal counterparts, the prima facie implausibility of Slice Theory - what Slice Theorists themselves consider "a problem that initially seems devastating" — can be countered. ${ }^{6}$ For example, one might protest that objects are quite unlike momentary temporal slices since objects persist through time and have histories while slices do not. But if temporal predicates apply to an object in virtue of counterpart relations, as Slice Theory claims, then we can explain why a temporal predicate applies to the object but not to the slice, all despite the fact that the object $i s$ the slice. "Tom" refers to a person, i.e. to a temporal slice; however, this slice has person counterparts with past and future slices whereas it doesn't have slice counterparts with past or future slices. Thus, we can say that this person was tall this morning and will exist tonight and this slice was not tall this morning and will not exist tonight, even though this person is this slice, for which counterpart relation a predicate invokes depends upon such contextual factors as which sort is salient. In this way Slice Theory hopes to do with cross-temporal counterparts what most do with referents that span time.

Both Worm Theory and Slice Theory analyze tensed predications as quantifiers over temporal slices - over all of the slices that make up the referent in the case of Worm Theory and over all of the slices I-related to the referent in the case of Slice Theory. The predicate is true of the referent iff such a slice at a time indicated by the tense, what I'll call a 'target slice', has the corresponding property. So far I have illustrated this with a simple predicate that can be analyzed in terms of a target slice having a property that holds merely in virtue of how that one slice is, i.e. a property that obtains merely in virtue of how things are at one particular time. The predicate 'tall' is true of the referent iff a target slice is tall, 'bent' is true of the referent iff a

\footnotetext{
${ }^{4}$ See, e.g., On the Plurality of Worlds.

5 “All the World's a Stage," p. 449; "How Things Persist”, pp. 42, 62.

6 Sider, “All the World's a Stage," p. 437.
} 
target slice is bent, etc. I will call these temporally intrinsic predicates. ${ }^{7}$ Other predicates, which I'll call temporally extrinsic, are analyzed in terms of the intrinsic properties of some slices other than a target slice. For example, the predicate 'is growing' is to be analyzed in terms of a continuous series of slices centered about a target slice, each of which must be larger than its predecessor. In the case of Slice Theory, these slices will be slices I-related to the target slice, and in the case of Worm Theory, these slices will be slices belonging to the worm centered on the target slice. Predicates such as 'is an ex-marine' and 'is a descendent of' will require similar, though increasingly complex, analyses.

This paper argues that Slice Theory is either inconsistent or a notational variant of Worm Theory. After characterizing Worm and Slice Theory a bit more, section I examines various problems with Slice Theory, arguing that the theory needs a simple fix: instead of saying that singular terms refer to current slices, Slice Theory should be guided by theories of reference and say either that they refer to those slices that fit the descriptions associated with the term or that they refer to those slices that are causally responsible for the use of the term. Section II argues that additional problems with Slice Theory as well as with Worm Theory are resolved once we recognize the temporal relativity of natural language quantifiers. Saying that there is one thing, or that this $i s$ that, or that this and that are the same is making a claim not of identity but of a relation that holds only relative to a particular time. Section III finally turns to compare Slice Theory with Worm Theory. The two theories differ in their identification of the referent of an expression and in their account of predication, but the two differences exactly compensate for each other such that the evaluation of any statement requires identical steps on either account. The claims used to characterize Slice Theory, however, are judged false according to the theory's own truth conditions, leaving us with a choice of either interpreting the theory charitably, in which case the theory doesn't really make the radical claims it appears to make, or taking its claims at face value, in which case the theory is inconsistent and should be dismissed.

If you're a temporal parts theorist, Slice Theory is not the way to go. My larger concern, however, should be of interest even to those eschewing temporal parts, for this examination of Slice Theory provides a test case, showing how semantic accommodation can undermine the metaphysical theory it is designed to save. Not only does this shed light on Slice Theory, one particular attempt at semantic accommodation, but it deepens our understanding of semantic accommodation in general and raises the specter that other such attempts are likewise doomed.

\section{Fixing Up Slice Theory}

Opponents of Slice Theory have raised various objections that Sider and Hawley have already shown to rest upon confusion. But I believe an additional problem stems from the particular formulation of Slice Theory that Sider and Hawley endorse. Consider a case of fission, a case in which Al splits like an amoeba into Cal and Hal. I will assume that a person persists through time in virtue of psychological continuity, though which theory of personal identity is correct is actually independent of the present point. Since Cal and Hal have, we will assume, identical memories up through the time of fission but gradually differing memories thereafter, Slice Theorists and Worm Theorists have concluded that the slices to be associated with the name 'Cal' include the slices prior to the fission called 'Al' and the slices following the fission called 'Cal'. Similarly, the slices to be associated with the name 'Hal' include the slices prior to the fission called 'Al' and the slices following the fission called 'Hal'.

\footnotetext{
7 The corresponding properties I call temporally intrinsic properties. Peter Simons calls these "time-blinkered properties" (Parts, p. 229). Perry calls these "basic" properties ("Can the Self Divide?" p. 470). Chisholm calls these properties 'rooted' in the time they are had (Person and Object, ch. 3).
} 
According to Worm Theory, an utterance at $\mathrm{t}$ of "Cal will be tall" is true iff a slice after $\mathrm{t}$ of the appropriate worm, i.e. the $\mathrm{Al} / \mathrm{Cal}$ worm, is tall. This sounds reasonable. (Assume the referent of 'Cal' was fixed prior to fission by some phrase such as "the person who will leave the duplication chamber wearing Al's coat'.) According to the formulation of Slice Theory we've been examining, however, an utterance at $t$ is true iff some slice after $t$ is tall and is I-related to the slice at $\mathrm{t}$ of the appropriate worm, i.e. the Al/Cal worm. When uttered after the fission we get the desired results, but if uttered before the fission, the sentence would be true iff a slice of the $\mathrm{Al} / \mathrm{Cal}$ worm or a slice of the $\mathrm{Al} / \mathrm{Hal}$ worm is tall, intuitively not at all what we want. ${ }^{8}$ In short, for cases of fission and fusion, it appears that something has gone wrong. ${ }^{9}$

There is a related problem. How do we analyze the sentence "Socrates was wise"? There is no current slice of Socrates, so we cannot apply the usual semantics. Sider claims that all tensed sentences are ambiguous between a de re and a de dicto reading, and to handle this as well as other problems he appeals to this ambiguity. ${ }^{10}$ Roughly speaking, on the de re reading "Socrates was wise" claims of Socrates himself, i.e. of the slice to which 'Socrates' refers, that

\begin{abstract}
${ }^{8}$ Sider has suggested (in correspondence) that we cannot refer, prior to the fission, to an individual Cal who is distinct from Hal. If such a reference is impossible, then the objection fails. I think we can refer to future individuals, though supporting this would require a lengthy tangent. Instead, though, we can consider the temporally symmetrical problem instead. That is, let's consider a case of Cal and Hal fusing to form $\mathrm{Al}$ and consider the sentence "Cal was tall" uttered after the fusion. We then have the same sort of objection, though it is not now open to problems concerning our ability to pick out future objects.
\end{abstract}

However, one might object that in cases of fusion there is not psychological continuity since Cal's and Hal's memories alter drastically at the time of fusion. Note, though, that the same considerations come into play with cases of objects rather than people, where spatio-temporal continuity seems to underlie so-called identity through time, and in these cases it is more difficult to maintain that the fission of, e.g., a wave and the fusion of two waves are not symmetrical.

${ }^{9}$ One response, suggested by Cian Dorr, Tim Maudlin, and Jeremy Pierce, is that I have been presupposing there is

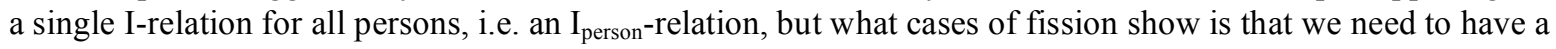
different I-relation for each individual. Thus, we get the correct semantics if we say: "Cal will be tall" is true iff a future slice is tall and is $\mathrm{I}_{\mathrm{Cal}}$-related to the current slice of the appropriate worm.

Such an approach is contrary to the usual counterpart-theoretic spirit, for the thought underlying counterpart theory is that the general identity conditions for being of some type $\mathrm{T}$ provide the necessary cross-temporal identity conditions for being a $\mathrm{T}$ and, hence, provide the information necessary for specifying the counterpart relations for all individuals of type T. Once one knows what it is in general to be a person, one thereby knows the counterpart relations in virtue of which we can evaluate claims about any particular person. It is easy to see how we can have knowledge of counterpart relations for a type, since learning what it is to be of that type is learning, inter alia, the identity conditions, and thus the counterpart relations, for being of that type. But if we are to countenance tokenrelative counterpart relations, how could we learn what constitutes a particular counterpart relation for a particular individual, especially an individual with whom we may not yet be acquainted? Intuitively, all I need to know about Cal to fully understand the truth conditions for "Cal will be tall" is that $\mathrm{Cal}$ is the person who will leave the duplication center tomorrow wearing Al's coat. How can learning this be enough to learn what the $\mathrm{I}_{\text {Cal }}$-relation is?

There is a simple response to my objection, for token-relative counterpart relations are simply type-relative counterpart relations constrained in some additional way. For example, person slices $\mathrm{x}$ and $\mathrm{y}$ are $\mathrm{I}_{\mathrm{Cal}}$-related iff $\mathrm{x}$

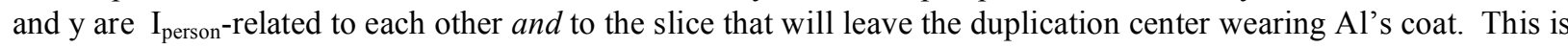
a notational variant of the modification to Sider's theory that I will be proposing. For, notice that the explication of the $\mathrm{I}_{\mathrm{Cal}}$-relation must talk of the slice which leaves the duplication center wearing Al's coat — this, after all, is what it is to be Cal. Thus, it seems much simpler and more natural to say that the slice to which we are referring is not the current slice but is instead the slice which will leave the duplication center wearing Al's coat. The current slice plays no role in the semantics and incorporating it as part of the semantics only complicates them.

10“All the World's a Stage," p. 450. 
he has the temporal property of having been wise, or, in other words, of being counterpart related to some prior slice which is (tenseless) wise. On the de dicto reading, in contrast, "Socrates was wise" asserts that "Socrates is wise" once was true; in other words, says Sider, this is not a claim about Socrates himself but one quantifying over past 'Socrates-stages', stating that one of those slices exists at a time prior to the utterance and is (tenseless) wise. ${ }^{11}$ And, argues Sider, while there can't be a de re reading of "Socrates was wise", since no particular slice stands out as a candidate for reference, there is a de dicto reading, and this reading gives us the correct truth conditions. Similarly, suggests Sider, we can employ this strategy to solve problems with fission. "Cal will be tall" doesn't receive the desired truth conditions if interpreted de re, but does if interpreted de dicto. ${ }^{12}$

Notice that a sentence can contain names of multiple people who aren't contemporaries, so the de dicto reading of a single past tensed sentence such as "Socrates was shorter than Lincoln" would require a quantifier over past times for each person named and thus cannot be understood as Sider suggests in terms of a single past tense operator applied to a present tensed sentence.

What worries me more, however, is that this strategy appeals to an ambiguity and to two different readings for evaluating tensed sentences where Worm Theory posits no ambiguity and appeals to a single reading. ${ }^{13}$ In fact, it looks as though Sider's de dicto reading gives us everything we need and the de re reading is otiose. If we can pick out the series of slices we need to quantify over for purposes of the de dicto reading — i.e., the so-called 'Socrates-slices' - and if in saying that Socrates was wise we're quantifying over those slices, why can't we go through the same process for people that currently exist and dispense with Sider's de re reading? And while the de re reading sounds simpler, the evaluation of a de re statement adds on an extra step to the evaluation of the corresponding de dicto statement. For example, if the name 'Ted' refers in virtue of a causal chain back to a baptism, then according to Sider the name 'Ted' will be tied to the slice that was so baptized. The name then refers to the current slice I-related to that baptized slice. And, finally, a sentence such as "Ted was seated" will be true iff some prior slice is seated and is I-related to the referent of 'Ted', which must in turn be I-related to the baptized slice. On a de dicto reading, in contrast, "Ted was seated" is true iff some slice prior to the

\footnotetext{
${ }^{11}$ The 'Socrates-stages' are the stages associated with the concept of Socrates. These can be either stages fitting the descriptive content of the concept, as descriptive theories of content have it, or stages I-related to that stage which was baptized as per causal accounts of reference. See "All the World's a Stage," § VII.

12 Moreover, Sider asks (in correspondence), for cases of fission aren't there in fact two ways we can interpret "Cal will be tall"? I would respond that the natural de re interpretation of the sentence does not make it true if either branch will be tall. There is, perhaps, a very extended sense in which the sentence can be given those truth conditions, but the explanation, I believe, is akin to the explanation of how I can correctly say "This ring was once a gold nugget lying on the bottom of that river." In both cases we are using one expression ("Cal"/"This ring") to fix upon a different, though closely related referent (Al/this gold).

13 And, because of problems with fission cases, this ambiguity is reflected in truth conditions that vary depending upon whether the referent still exists or not. If Einstein underwent fission or fusion, the truth conditions for "Einstein invented the bomb" differ depending upon whether he is currently living. For example, if Einstein fused with Smith, after which the resulting person was called "Smithstein", then Sider tells us (at least if some Kripkeinspired causal theory of reference for names is correct) that the Einstein-stages are those that were called 'Einstein' and those called 'Smithstein' (these are the stages I-related to the stage dubbed 'Einstein'). Intuitively this seems correct. But then we have a problem, for 1) if Einstein (i.e., Einstein-cum-Smithstein) is still alive, the sentence has a reading on which it is true iff some slice(s) called 'Einstein', some slice(s) called 'Smithstein', or some slice(s) called 'Smith' invented the bomb; and yet 2) if he is not alive the sentence is true iff the slices called 'Einstein' or the slices called 'Smithstein' invented the bomb. (See “All the World's a Stage," p. 449.)
} 
utterance that is seated is I-related directly to the baptized slice. Hence, in cases where the referent slice exists (the only case we can use a de re reading), the de re reading will be equivalent to the de dicto reading as long as the I-relation is transitive. As argued above, though, Sider's semantics get the truth conditions wrong when the I-relation is not transitive, as in cases of fission and fusion. So when Sider's de re reading is possible, the analysis is at best more complex but equivalent to the analysis for the de dicto reading.

In addition, Sider's de re reading is not, after all, a reading that captures what have traditionally been considered de re readings of ambiguous sentences. "Martha believes Socrates was wise" does have a de re reading as usually construed, i.e., one on which Martha believes of Socrates (even though she may not know his name but knows him only by acquaintance prior to his death) that he is wise, yet it doesn't have what Sider is calling a de re reading, since there is no current slice of Socrates. ${ }^{14}$ Moreover, we can capture what is traditionally wanted with de re readings even using what Sider is calling a de dicto reading. The traditional de re reading of the statement "Martha believes Socrates was wise" can be captured by quantifying over the Socrates slices and saying that Martha believes of (at least) one of them that he is wise. Of what use, then, is Sider's de re reading?

A Worm Theorist already needs the distinction between de re and de dicto to handle the usual sorts of cases, but she needn't say that everyday past or future tense sentences are ambiguous in this way. ${ }^{15}$ Moreover, it seems that the truth conditions that we would get with Slice Theory using the de dicto readings will be exactly the same as what Worm Theory delivers: "Socrates was wise" is true iff some slice of the Socrates worm is wise. Thus, if Worm Theory does have problems, as Slice Theorists aver, incorporating the Worm Theory semantics for all de dicto readings will mean that Slice Theory will inherit exactly those problems that were supposed to show us that Slice Theory is preferable to Worm Theory.

I suggest that the problem with Slice Theory lies with the claim that terms refer to current slices. Whether my reference to Tom obtains in virtue of the descriptions I associate with the name - e.g. that Tom was my second grade teacher - or in virtue of causal connections I've had with Tom - either the direct causal connection obtaining in virtue of me seeing Tom in second grade or the indirect causal connection between my hearing of Tom's name and Tom's original dubbing - these are not satisfied in any direct way by the current slice. If we are to pick out a single slice of the worm to which we are referring, it seems that our theory of reference should dictate which slice it is. But if not to the current slice, to which slice do we refer?

One possibility is to say that names refer to the slice initially dubbed by that name. In spirit, this is a move in the right direction, for we are now choosing the referent slice using considerations that are, at heart, the same as those that have been used by theories of reference more generally, i.e. theories that are neutral with respect to the ontology underlying our talk of objects. And, it seems, the choice of a referent slice should be motivated by our best theory of reference. Just as Kripke sought a connection to a unique referent object and found a solution with the causal tie to the dubbing, so too can we as Slice Theorists find a solution with a Kripkean account of the connection to a unique slice.

\footnotetext{
14 I owe this point to Troy Cross.

15 The de re vs. de dicto distinction is commonly motivated by ambiguities that come with opaque contexts. For example, the sentence "Jo thinks that someone plays bocce" can either mean Jo thinks there are bocce players or that there is someone such that Jo believes of that person that they play bocce. The existential quantifier ('someone') falls within the scope of the belief report in the former case and falls outside it in the latter.
} 
However, I think the same considerations that weigh against Kripke's account as a theory of reference in general also suggest that a Kripkean account is inadequate as a theory of reference to slices. For one thing, it is difficult to see how to generalize Kripke's causal theory of the reference of names, for presumably the correct theory of reference should generalize to pronouns, demonstratives, etc. For present purposes, I do not care which theory of reference is correct since it seems that almost any means used by the Worm Theorist to select the worm that she considers the referent can be adopted by the Slice Theorist to select the slice that he considers the referent. However, while I have no desire to get sidetracked into a discussion on the correct theory of reference, I do need to sketch some arguments for theories of reference in order to defend the claim that Slice Theory can simply adopt whichever theory is correct. So let us push beyond the Kripkean theory.

Let's return to the case of Al who splits into Cal and Hal. Suppose I met Al before the fission, though I did not learn his name. Now, after the fission I say, "Let me dub that fellow Todd." If we're going to follow the idea that names refer to slices, then any claim I make about Todd should, intuitively, refer to a pre-fission slice, even though the dubbing occurred after the fission. This suggests that the dubbed slice is not the slice existing at the time of the dubbing but is the slice with which the dubber is acquainted. Of course, I might have thought back to my meeting with $\mathrm{Al}$ and just said, "That fellow sure was friendly" without using any name, in which case it still seems that I'm referring to the slice with which I was acquainted. And, hearing my words, you might even say you'd like to meet 'him', referring to Al by piggybacking off my reference, suggesting that some sort of causally mediated acquaintance is also sufficient for reference.

Similarly, what if I met Al briefly prior to his fission, but have long forgotten that meeting and have since become close friends with Cal after the fission, never learning that $\mathrm{Cal}$ goes by the name 'Cal' and thinking of him still as 'Al.' If I say, "Al and I are great friends, and $\mathrm{Al}$ is short," it seems what I mean is that Cal is short, not Hal. So it seems in this case we want to use a slice following the fission. Again it seems acquaintance is the key. In case it seems I'm confusing speaker meaning with linguistic meaning, we can alter the case a bit. Shortly after the fission Hal moved away and, since nobody even knew about the fission and Cal himself forgot it due to a case of amnesia, Cal still goes by his old name, viz. 'Al.' Nonetheless, if I meet Cal and later say, "Al is short" it seems that I'm making a statement about Cal rather than Hal; that is, in this case we are again referring to a post-fission slice of Cal's.

I will not take this investigation further, for objections to Kripke's theory have long ago appeared in the literature on theories of reference. ${ }^{16}$ So let me shift venues to some old theories of reference, i.e. reference to objects in general rather than reference to slices.

\section{Evans' Causal Theory of Reference}

According to Evans' causal theory of reference, the object to which I refer with a name is that object causally responsible for the beliefs I associate with that name. ${ }^{17}$ Thus, if I believe Washington was the first president, had false teeth, and was named 'Washington', each of these beliefs can, presumably, be traced back to Washington. Washington became the first president, and that event caused various people to think he was the first president which caused ... which caused someone to write in a book that he was the first president which caused me, upon reading that book, to believe that he was the first president. Perhaps Washington's teeth chattered and this was in fact the original cause of the false belief that he had wooden teeth; nonetheless, since

\footnotetext{
${ }^{16}$ See, e.g., Evans' "The Causal Theory of Names."

17 "The Causal Theory of Names."
} 
it was Washington's teeth and not someone else's that chattered, he is the ultimate source of my belief that he has false teeth, and so it is to him that I refer when I speak of 'Washington'.

No doubt there are many cases in which there are multiple causal sources of the beliefs I have about something. Evans thought the referent was the dominant source of beliefs, but for ease of exposition I will follow Kvart who considers these cases of 'divided reference'. ${ }^{18}$ Thus, if it was actually Franklin who had the wooden teeth and if, through some mix-up, he was the source of my belief that Washington had wooden teeth, then in speaking of 'Washington' I am in some sense partially referring to Franklin. The notion of divided reference has intuitive appeal if I tell you that I admire Washington, our white-haired thirteenth president who freed the slaves, since it was Washington who was named 'Washington' and had white hair yet it was Lincoln who was the thirteenth president who freed the slaves. ${ }^{19}$ Cases of divided reference will be important when adapting Evans' theory to Slice Theory.

I think Evans' theory of reference comes closer to the correct account than Kripke's, though I think the full story is yet more complicated. However, as mentioned, for my purposes it does not matter which theory is correct. I will merely presuppose Evans' theory for now since it has some intuitive appeal and since it raises various complications that we must consider.

\section{Altering the Standard Account: Changing the Referent Slice}

With Evans' causal theory roughly characterized, let's return to our examination of the view that we refer to slices rather than to objects that span time. We can now change the semantics of Slice Theory to say that a name does not refer to the current time slice of an object but to the time slice causally responsible for the speaker's beliefs associated with that name. If I know of Renata only by seeing her photo once, then when I refer to her I am referring to the time slice of Renata that was photographed. Thus, an utterance of "Renata is in New Jersey" at $t$ is true iff a time slice in New Jersey at $t$ is I-related to the time slice that was photographed. An utterance of "Renata was in New Jersey" at $t$ is true iff a time slice that is in New Jersey prior to $t$ is I-related to the time slice that was photographed. Demonstratives, second-person indexicals, and even first-person indexicals presumably also refer to the object that caused those beliefs the speaker associates with that use of the term. ${ }^{20}$

This change to Slice Theory overcomes the problems we found before. An utterance of "Socrates was short" at $t$ is true iff a time slice prior to $t$ both is short and is I-related to the time slice that is causally responsible for the speaker's beliefs concerning 'Socrates'. Thus, references to dead people are now handled in a way no different than references to the living.

\footnotetext{
18 Igal Kvart, "Divided Reference,” Midwest Studies in Philosophy, Vol. XIV, 1989, pp. 140-179.

19 And perhaps we should weight our different sources of beliefs differently, even across various acts of referring. (As Evans says, "the believer's reason for being interested in the item at all will weigh." See his "The Causal Theory of Names," p. 303.) If I were told that it was not Washington but Lincoln who freed the slaves, it would be natural for me to say that in that case it was Lincoln I meant when I said how much I admire Washington. If I then say that I like Lincoln's hair and am told that it was actually Washington who had the white hair, it would be natural for me to say it was Washington I meant in this case.

${ }^{20}$ For example, if I say "You look tired" to the person I think of as 'Martha Rimsky', then 'you' refers to whoever is causally responsible for the beliefs I have in my 'mental file folder' with information on 'Martha Rimsky', most salient of which would be the belief that I am talking to her at that time.
}

This allows demonstrative references to things that no longer exist. If I point up to 'that' in the sky, perhaps the star I am seeing exploded long ago. And it seems that "I saw you at a party", appearing in a letter, can be true even if the addressee died before the words were written. 
There is no need for a different mechanism, and, more importantly, one need not know whether the referent is still alive to know how to evaluate the sentence.

Similarly, the problems with fission and fusion disappear. If I speak of $\mathrm{Al}$, my knowledge of Al is, ex hypothesi, caused by a time slice prior to the fission. Therefore, since reference is made to the slice causally responsible for the speaker's beliefs, the truth value of a timeless sentence does not vary with the time of utterance as it does with the semantics offered by Sider and Hawley. Utterances of "Cal will be tall two hours after the fission," will have the same truth condition, and hence the same truth value, whether the utterance is made before or after the fission, just as we would expect.

When I refer to most objects and persons, I have multiple sources of information about them and, hence, my reference is 'divided'. That is, if we are referring to slices rather than worms, then I will in fact be referring ambiguously to a multitude of stages. When I speak of Mom, I am referring to that slice that I saw when I first opened my eyes as a baby, I am referring to that slice I saw a millisecond later, and so forth, including an infinitude of slices up through the slice that finished saying "Good-bye" when I was last on the phone with her. But these are 'unproblematic' cases of divided reference. Any claim I make about Mom will be equally true or false no matter which slice we take as my reference. This is guaranteed by the fact that all 'Mom' slices are I-related to each other and to no other slices. ${ }^{21}$

The only 'problematic' cases of divided reference we could encounter would be cases of fission and fusion, that is, cases that should be ambiguous at the level of the sentence. If I met $\mathrm{Al}$ before the fission, and met Cal after the fission, not knowing about the fission and thinking of this also as 'Al,' then my statement "Al is tall" will be a case of problematic divided reference, since the truth conditions are ambiguous between saying that the current slice of Cal is tall, if I'm referring to a post-fission slice, and saying that the current slice of Cal or Hal is tall, if I'm referring to a pre-fission slice. This, however, just parallels the ambiguity that the worm account will encounter, an ambiguity we expect to find.

I have used Evans' causal theory of reference to help illustrate how we can accommodate a theory referring to slices rather than worms. But we can also consider a descriptivist theory of reference. There will be the usual problems of fixing upon a single referent using descriptions, and perhaps one taking this line will take a cue from causal theories and incorporate into the descriptivist theory some requirements for causal relations. One may think, though, that a descriptivist reference to a slice involves additional problems over a descriptivist reference to a worm. If I say that 'Shorty' will be the name, applied rigidly, for whoever is currently the shortest spy, then assuming names refer to slices, any sentence using this name will refer to the slice of the shortest spy at the time of my dubbing. If, on the other hand, I say that 'Shorty' is to name the shortest spy in 1990, then, if the shortest spy had the same height throughout the year, there is no way to fix upon a unique referent. However, this too will simply be a case involving an unproblematic divided reference - unless, of course, different spies were equally short at different times during 1990, in which case we want our theory to deliver a problematic divided reference. Whether we are considering a causal theory or a descriptivist theory, cases in which an expression refers equally well to a multitude of slices do not necessarily bring indeterminacy at the level of the sentence.

\footnotetext{
${ }^{21}$ Unproblematic cases of divided reference are those in which the slices causally responsible for the belief all have the same set of I-related slices. Thus, a sentence involving a term with a divided reference is not unproblematic merely in virtue of the truth value of the sentence being the same on either disambiguation.
} 


\section{Problems With Sameness}

Several objections to Slice Theory as well as some to Worm Theory ride on how we are to understand natural language quantifying expressions such as 'the same' and 'one'. I will first argue that such expressions have been misunderstood and then show how various objections to Slice Theory and Worm Theory are resolved with the proper understanding of our quantifiers.

According to the usual characterization, identity is transitive, symmetrical, reflexive, and obeys Leibniz's Law, which says that $\mathrm{x}=\mathrm{y}$ only if $\mathrm{x}$ and $\mathrm{y}$ have identical properties. The puzzle comes when we consider things that differ merely temporally or modally. A lump of clay sat in my garage for a week, but just this morning I formed it into a statue and placed it on my mantle. The lump existed yesterday, though the statue did not. Following Leibniz's Law, we must say the lump of clay and the statue are not identical, for they differ in their temporal properties.

Common sense, however, insists that the lump of clay is a statue and that there is only one object on the mantle. The apparent tension is dissolved, I believe, once we notice that our everyday judgments about sameness treat modal and temporal properties differently than ordinary properties. If we tell the non-philosopher that the lump of clay sat in the garage last week and the statue was created just this morning, she is not at all motivated to deny that there is only one object on the mantle. But if we instead tell her that the lump of clay is painted entirely white and the statue is painted entirely black, then she will conclude that we must, after all, be talking about two different objects.

Why this difference? Simply because when we claim that one thing is another, or that there is only one thing, or that one thing and another are the same thing, typically we are not saying that they share all properties but only that they share all properties intrinsic to the contextually specified time and world. That is, we are not saying that they are identical but only that they are related by what I will call sameness. English allows that $\mathrm{b}$ and $\mathrm{c}$ were or will be different things and yet that $\mathrm{b}$ and $\mathrm{c}$ are nonetheless now 'the same' thing. ${ }^{22}$ A fortiori, English allows that $\mathrm{b}$ and $\mathrm{c}$ could have been different and yet that $\mathrm{b}$ and $\mathrm{c}$ are nonetheless actually 'the same' thing.

Thus, I am suggesting that 'the same' is ambiguous, and, as a result, that philosophers have conflated the absolute relation of identity with the temporally and modally relative relation of sameness. Failing to distinguish the two, philosophers have tried to accommodate conflicting desiderata. On the one hand they share everyday intuitions that there is only one object on the mantle and that in cases of fission what was one person becomes two people, and yet on the other hand they are unwilling to disclaim Leibniz's Law or the transitivity of identity. The result has been a congeries of fantastic metaphysics denying common sense, all of which can be avoided simply by recognizing the temporal relativity of our quantifiers.

The ambiguity I am highlighting is not new. According to White and to Rea, Aristotle relied on a quite similar distinction. ${ }^{23}$ Wiggins, Johnston, and Thomson have distinguished the 'is' of identity from the temporally and modally relative 'is' of composition. ${ }^{24}$ It is true, they would urge, that 'the lump of clay is a statue', but that is because this means simply that the statue is composed of a lump of clay, i.e., is now composed of a lump of clay. Perry, Robinson,

\footnotetext{
${ }^{22}$ Cian Dorr, describing his experience teaching undergraduates about the statue and the clay (personal correspondence), said the students "showed an unshakeable determination to say things about it that didn't make sense (stuff about how the clay 'takes on the identity of' the statue, etc. etc.)." But perhaps a charitable way to interpret these claims is as saying that the clay becomes 'the same thing' as the statue.

${ }^{23}$ White, "Identity, Modal Individuation, and Matter in Aristotle"; Rea, "Sameness without Identity."

${ }^{24}$ Wiggins, Sameness and Substance; Johnston, "Constitution is not Identity"; Thomson, "The Statue and the Clay."
} 
and Lewis distinguish two ways in which we count things. ${ }^{25}$ According to one way, the statue and the lump of clay are two things, for they differ modally, if not temporally. According to the other, the statue and the lump of clay are one thing, for to count in this way is to count by identity-at-t, i.e. to count in a temporally relative way. All of these philosophers, each in their own way, are pointing out a temporally and/or modally relative relation that must be distinguished from the absolute relation of identity.

We can now spell out the semantics for temporally relative claims of objects being 'the same'. For Worm Theory we have:

" $b$ and $c$ are the same $F$ at $t$ " is true iff ' $b$ ' and ' $c$ ' refer to worms that 1) satisfy the

identity conditions for being $\mathrm{F}^{\prime} \mathrm{s}$, and 2 ) have identical slices at t. ${ }^{26}$

And, correspondingly, for Slice Theory we have:

" $\mathrm{b}$ and $\mathrm{c}$ are the same $\mathrm{F}$ at $\mathrm{t}$ " is true iff ' $\mathrm{b}$ ' and ' $\mathrm{c}$ ' refer to slices that 1) satisfy the identity conditions for being $\mathrm{F}^{\prime} \mathrm{s},{ }^{27}$ and 2 ) are $\mathrm{I}_{\mathrm{F}}$-related to a single slice at $\mathrm{t}$.

According to both theories, saying that $\mathrm{b}$ and $\mathrm{c}$ are the same $\mathrm{F}$ is to say two things. First, it says that both $\mathrm{b}$ and $\mathrm{c}$ are F's. Second, it says that $\mathrm{b}$ and $\mathrm{c}$ are the same, but for Worm Theory this is a sort-independent relation of sameness (at $\mathrm{t}$ ) whereas for Slice Theory this is a sort-relative sameness (at $\mathrm{t})$ relation.

So far I have suggested that the relation often picked out by everyday uses of 'the same' holds relative to a contextually relevant time. One may object, though, that with this sense of 'the same' we cannot say that $b$ at $t_{1}$ is the same as $c$ at $t_{2}$. That is, there doesn't seem to be any means of having a cross-temporal relation whereby $b$ and $c$ are related by sameness. And, the objection continues, English clearly allows such talk: "I am the same person who waved to you yesterday." The same problem seems to occur with cases of fission as well. If Cal and Hal are the products of Al's fission, then prior to the fission we can say, "Cal, who is standing here now, and Hal, the person who will marry Sheila next year, are the very same person."

We might simply say that such cross-temporal claims of things being 'the same' are invoking absolute identity, since some claims of things being 'the same' might well invoke absolute identity. But I think we can also accommodate such sentences with a relation that only relates things at a single time. For while the relation invoked by 'the same' does not span times, the things related, or at least their counterparts, commonly do, and thus these things can be identified by properties they, or their counterparts, have at other times. The sentence "I am the same person who waved to you yesterday" claims that sameness obtains now between the referent of 'I' and the referent of 'the person who waved to you yesterday', though these things now related by sameness also have features obtaining at other times, e.g. the latter's waving to you yesterday. Of course, I and the person who waved to you yesterday are absolutely identical, so they are also related by sameness at all times at which they exist, but perhaps the correct interpretation of this sentence is that it is only asserting sameness at a time, something weaker than absolute identity. In contrast, while Cal and Hal are now 'the same,' after the fission when

\footnotetext{
${ }^{25}$ Perry, “The Same F,” pp. 198-199; Lewis, On the Plurality of Worlds, p. 218; Lewis, “Survival and Identity,” p. 63; Robinson, "Can Amoebae Divide Without Multiplying?"

${ }^{26}$ I say sameness requires the two worms having identical slices. More generally I should say they have slices that are identical in all non-modal properties, for we might want to leave open as a possible form of Worm Theory a version which says that multiple slices can occupy the same spatio-temporal region yet differ modally. I will omit such niceties, though, since most advocates of Slice and Worm Theory deny such coincidence.

27 To say that a slice s satisfies the identity conditions for being an $\mathrm{F}$ is to say that $\mathrm{s}$ is an $\mathrm{F}$ slice (i.e. satisfies the spatial requirements for being an $\mathrm{F}$ ) and is $\mathrm{I}_{\mathrm{F}}$-related to a series of $\mathrm{F}$ slices that span an interval such that those $\mathrm{F}$ slices together satisfy the persistence conditions for $\mathrm{s}$ being an $\mathrm{F}$.
} 
Hal marries, they will not be. Hal persists through time: next year he will marry, but now he is 'the same' as Cal. Thus, a statement claiming that two things 'are' the same can be understood as predicating sameness now even if it identifies the relata in terms of properties they have at past or future times. ${ }^{28}$

From the perspective of Worm Theory, sameness at $t$ is the relation of sharing a slice at $t$. Thus, if two worms overlap for some interval and that interval includes the time $t$, then the two worms are 'the same' at t. Of course, a common case in which b and c are said to be 'the same' is when they are absolutely identical, in which case they will be the same at all times at which they exist. From the perspective of Slice Theory, $b$ and $c$ being 'the same' at $t$ is the relation of $b$ being I-related to some slice at $t$ to which $\mathrm{c}$ is I-related. Again we can picture this by thinking of the worm consisting of all slices I-related to $b$ (what Worm Theory says is the referent of ' $b$ ') and the worm consisting of all slices I-related to c (what Worm Theory says is the referent of ' $c$ '); $b$ and $\mathrm{c}$ are then 'the same' at $\mathrm{t}$ iff these worms overlap at $\mathrm{t}$.

\section{Addressing Objections Based on Sameness}

With the temporal relativity of 'the same' clear, let's now look at some objections which it dissolves. Sider concedes that Slice Theory "has costs", for, he says, the

concern is this: the fact that I was once a child and will one day be an old man is, according to the stage view, really a fact about two different objects, a stage that is a child and a stage that is an old man. ${ }^{29}$

We need to be careful, though, just what the "legitimate cause for concern" is. ${ }^{30}$ Sider points out that according to Slice Theory, statements that he will one day be an old man and that he was once a child are statements about him, a single slice. And this, he argues, shows that the most common reason for rejecting Slice Theory is misguided. He concedes, however, that these statements are to be analyzed in terms of two different objects, the child and the old man. And yet, runs the objection, intuitively these sentences should be analyzed in terms of a single object, the persisting person who was a child and will one day be an old man. However, given the recently defended semantics for 'the same', we can see that the child he once was and the old man he will become are properly said to be 'the same person' since the two slices are I-related to a single slice at the time indicated by the tense. It is therefore unclear what, if anything, is left of this objection to Slice Theory.

Similarly, Sider admits that "When I look back on my childhood, and say 'I am that irritating young boy', the stage view pronounces my utterance false." 31 But, once again, though it is true that "the slice that is a child, the current slice that is Sider, and the slice that is an old man are not identical slices," it is also true that "they are all the same person." Moreover, we need to consider whether the claim, "I am that irritating young boy" is a tensed or a tenseless statement. If this is a tensed statement of English, the statement is true according to Slice Theory, for all that is required is that the referent of ' $\mathrm{I}$ ' and the referent of 'that irritating young boy' be I-related to a single current slice. Thus, unless this must be interpreted as a tenseless claim, a topic we will soon visit, Sider's concession is not necessary.

Considering a similar objection to Slice Theory, Sider sees himself as forced to make 'a partial retreat'.

\footnotetext{
${ }^{28}$ And, likewise, statements can predicate sameness at past or future times even if they identify the relata in terms of properties they have at other times: "My uncle, who is now in Chicago, was the same person who talked to you yesterday."

29“"All the World's a Stage," p. 447.

30 "All the World's a Stage," p. 447.

31 "All the World's a Stage," p. 446.
} 
If we take the 'timeless perspective' and ask how many people there ever will be, or how many people have been (say) sitting in my office during the last hour, the stage view seems not to have an easy answer. ${ }^{32}$

But this too is now easy to answer. There were an infinitude of slices that sat in my office during the last hour, but according to our semantics for English claims of sameness these are all the same person. ${ }^{33}$

Actually, we have only looked at the semantics for tensed English claims and Sider asks us to take the 'timeless perspective', so we need to determine how a tenseless predication of being 'the same' applies to the various slices that sat in my office this morning. I have advocated a temporally relative sense of 'the same', but isn't there also an absolute notion as well? It seems so, for the sentence "Nine people have climbed the south face of Lhotse" can be true even if the nine people lived at distinct periods of history and so there is no single time at which one could count using sameness. And if there are timeless, or tenseless, sentences which say things are 'the same', it looks like they could not employ a temporally relativized notion of sameness since there is no time specified by the tense relative to which sameness can be assessed. ${ }^{34}$

So what does it mean for $\mathrm{x}$ and $\mathrm{y}$ to be 'the same' in a tenseless way? One natural thought is that this simply means, or at least requires, that $\mathrm{x}$ and $\mathrm{y}$ be the same at all times, rather than, as a tensed understanding would have it, at only the one time indicated by the tense. After all, while we can understand tensed statements saying that $\mathrm{x}$ and $\mathrm{y}$ are the same thing but $\mathrm{x}$ existed at $t$ and $y$ didn't - this is what people often say about the statue and lump of clay - it is hard to make sense of such a statement that is untensed. And yet, since we've already seen that $\mathrm{x}$ and $\mathrm{y}$ being the same at some time $\mathrm{t}$ requires, on Slice Theory, that $\mathrm{x}$ and $\mathrm{y}$ are I-related to the identical slice at $\mathrm{t}$, this means that $\mathrm{x}$ and $\mathrm{y}$ being tenselessly the same would require $\mathrm{x}$ and $\mathrm{y}$ being I-related to the same slices at all times. A similar thought is that we should invoke Leibniz's Law and say $\mathrm{x}$ and $\mathrm{y}$ are tenselessly the same only if they have identical properties, including temporal and modal properties. ${ }^{35}$ However, because Slice Theory understands predications of temporal and modal properties using counterpart relations, this also means $\mathrm{x}$ and $\mathrm{y}$ would be (tenselessly) the same $\mathrm{F}$ only if $\mathrm{x}$ and $\mathrm{y}$ were $\mathrm{I}_{\mathrm{F}}$-related to all of the same slices. The

32 "All the World's a Stage," p. 448.

${ }^{33}$ Hawley also defends Slice Theory by appealing to a relation she calls 'sameness', though for her this is the Irelation (How Things Persist, §2.8), a cross-temporal relation that is not temporally relative. She appeals to this to reconcile our counting practices with how many objects there are counting by identity. The temporally relative relation, I suggest, is independently motivated, as witnessed by the large number of philosophers not pursuing Slice Theory that have advocated such a relation. The relation that Hawley suggests, in contrast, is, by her own lights, ad hoc and therefore a cost to the theory (How Things Persist, p. 64).

${ }^{34} \mathrm{I}$ in fact think that a pragmatic account will supply the times required for temporally relativized uses of 'the same', and thus that ordinary claims (such as "Nine people have ...") and tenseless claims need not employ an unrelativized use of 'the same'. As evidence, notice that the statement "Lincoln was taller than Socrates" requires some mechanism which provides the times at which Lincoln and Socrates have the relevant heights. Thus, there is already a general mechanism which provides the relevant times at which we are to consider subjects. However, for present purposes I will not rely on this view.

35 One might object that the temporal and modal 'properties' of objects that I have been discussing are not genuine properties, for whether it is true to say that something existed yesterday is relative to a contextually specified sort. The lump of clay existed yesterday, but the statue did not, even though 'the lump of clay' and 'the statue' refer to the same slice. The temporal properties of the slice, a Slice Theorist might insist, are, more properly, being $\mathrm{I}_{\text {lump- }}$ related to a slice yesterday and not being $\mathrm{I}_{\text {statue }}$-related to such a slice, and therefore the temporal properties of the statue do not differ from those of the lump of clay. (This parallels the response a modal counterpart theorist would give.) 
key idea in Slice Theory is to use temporal counterparts to trade talk of objects having properties at $\mathrm{t}$ for talk of slices bearing counterpart relations to slices at $\mathrm{t}$ that have corresponding temporally intrinsic properties. There seems to be no reason that this general schema would apply only to tensed predications.

Let's suppose, though, that Slice Theory were spelled out such that tenseless statements were not analyzed using temporal counterparts. In this case, we do not get merely the disagreement with common sense concerning, e.g., counts of people who have occupied my office in the last hour. Rather, most tenseless statements would disagree with common sense. For example, though the tensed statement "Ted played basketball in 2003" is judged true by Slice Theory, agreeing with common sense, the tenseless correlate, "Ted plays basketball at some t during 2003" is judged false since the referent of 'Ted', let us assume, is some slice that did not exist in 2003 and it is only by using temporal counterparts that we get from the referent slice, which did not exist in 2003, to some slice that does exist in 2003 and was playing basketball. Thus, if the theory does not employ temporal counterparts in the analysis of tenseless statements, the theory would systematically disagree with common sense both regarding the truth of tenseless statements and regarding which inferences (e.g., between tensed and tenseless statements) would be warranted, exactly what we would expect of a theory that has a mistaken analysis of tenseless statements. ${ }^{36}$

Thus, even understood as a tenseless claim, b being 'the same F' as c will still be spelled out in terms not of $\mathrm{b}$ and $\mathrm{c}$ being identical slices but of $\mathrm{b}$ and $\mathrm{c}$ bearing the appropriate I-relations to identical slices, and, given this understanding, I am that irritating young boy, and only a single person sat at my desk this morning, viz. me.

The next objection is that according to the Slice Theory, objects do not persist through time. Sider answers this as follows:

If by 'Ted persists through time' we mean 'Ted exists at more than one time', then the stage view does indeed have this consequence. But in another sense of 'persists through time', the stage view does not rule out persistence through time, for in virtue of its account of temporal predication, the stage view allows that I both exist now and previously existed in the past. Given that the stage view allows the latter kind of persistence, I think that the denial of the former sort is no great cost. ${ }^{37}$

In fact I think that Sider has again not gone far enough. What does it mean to say 'Ted exists at more than one time'? Presumably we are to think of Ted in the natural, pre-theoretic way as a person rather than a slice. It seems that 'exists' is not a present tense claim since it's not indicating that right now Ted exists at more than one time. ${ }^{38}$ Perhaps, then, this is some sort of tenseless claim. However we are to analyze the claim, it seems it must require that Ted did, does, or will exist at more than one time. But this too is easily accommodated by Slice Theory, as Sider notes. It seems that any analysis of tenseless English statements that follows the same approach, i.e. applying temporal counterparts, will give us the desired truth conditions for sentences concerning the times objects exist.

Other similar objections also dissolve given the temporal relativity of everyday claims of sameness. For example, one might complain that you and I are referring to different people when we talk about Bob, since different slices are responsible for your and my beliefs about Bob. But even though we may be referring to different slices, we nonetheless are, as the semantics show, referring to what is the same person. Or, as another example, one might question my

\footnotetext{
36 Such systematic conflicts with common sense will be examined more closely in the section, 'Confusing Languages'.

37“"All the World's a Stage,” p. 446.

38 This is none too clear since there are 'relative' tenses.
} 
attempt to explain away potential problems with ambiguous references as 'unproblematic ambiguity'. For, consider the phrase 'the shortest spy of 1990'. A Russellian analysis of 'the' requires a unique referent, and yet according to Slice Theory there may be no such unique referent since the shortest spy may have had the same height at different times in 1990. But, again, there is a single person, at least as we individuate people in English; it is only as a claim talking about slices that we can say there are multiple referents.

Finally, we can dissolve a supposed advantage of Slice Theory. According to Sider, Worm Theory has costs because "the idea that in fission cases there would be two persons in a single place at one time is preposterous." 39 But we can defend Worm Theory using the same understanding of 'the same' we have been using to defend Slice Theory. Individuating things by their temporally intrinsic properties, i.e. counting by identity-at-t, there is only one person at a place. Both Worm Theory and Slice Theory agree on this, for on these theories counting people individuated by their temporally intrinsic properties just is counting slices. Thus, Worm Theory is not committed to the English claim that there are multiple co-located people. On the other hand, individuating things by their temporally extrinsic properties, there are, prior to the fission, two worms in a single place. But again, both Worm Theory and Slice Theory agree on this, for on either theory, worms are the result of individuating people by their temporally extrinsic properties. In other words, if we are counting objects by absolute identity, i.e. individuating objects by their temporally extrinsic properties, then Slice Theorists must also agree that Cal was present before the fission, Hal was present at the same place and time, Cal was sitting down one hour after the fission and Hal was not sitting down one hour after the fission, and therefore there were in this sense 'two people' in a single place prior to the fission.

\section{How Similar are Worm Theory and Slice Theory?}

With some of the purported differences between Worm Theory and Slice Theory dismissed, we begin to see that in fact the semantics of Slice Theory are surprisingly similar to the semantics of Worm Theory. Let's compare the two. Recall that with Worm Theory we have:

"Tom was tall" is true at $\mathrm{t}$ iff a slice 1) belongs to the worm referred to by 'Tom', 2)

exists before $t$, and 3 ) is tall.

Correspondingly, with Slice Theory we have:

"Tom was tall" is true at t iff a slice 1) is I-related to the slice referred to by 'Tom', 2)

exists before $t$, and 3 ) is tall.

Both say that some slice is tall. Both require that slice to precede the time of utterance. We are left with a single difference between the two accounts: Slice Theory requires that the slice be $I$ related to the referent slice, while Worm Theory requires that the slice be a slice of the referent worm.

However, even this difference dissolves upon closer inspection, for being a slice I-related to what Slice Theory calls 'the referent slice' just is being a slice of what Worm Theory calls 'the referent worm'. Whether the correct theory of reference relies upon causal connections or fitting descriptions, the same underlying mechanism can be adopted equally well by an account that says that our expressions refer to slices or by an account that says that our expressions refer to worms. The theory of reference that says that my utterance of 'Tom' refers to a slice (or, ambiguously, to some slices) will pick out that slice (or those slices) that satisfies my beliefs about Tom or that caused me to have my beliefs about him. The theory of reference that says that my utterance of 'Tom' refers to a worm will pick out that worm that satisfies my concept of

39“"All the World's a Stage," p. 439. 
Tom or that caused me to have my beliefs about him. Remember, though, that according to Worm Theory the worm that satisfies some temporary intrinsic predicate (e.g., 'being bent') does so derivatively in virtue of being a sum of I-related slices, one or more of which satisfies the predicate in a more basic way. So the worm that satisfies my concept of Tom or that caused me to have my beliefs about him will simply be the sum of all slices I-related to the slice that satisfies my concept or that caused me to have my beliefs about him. Thus, Slice Theory and Worm Theory give different accounts of reference and different truth theories in terms of these referents, but the one difference compensates for the other. The net result is that, once we cash out all talk of 'the referent' in more basic terms of what is required for reference, the two accounts generate exactly the same truth theorems!

\section{A Thoroughgoing Parallel?}

As we have seen, Worm Theory and Slice Theory go through the same steps to determine whether a sentence is true. Under both theories, to determine if "Tom was tall" is true, we find a slice $s$ that is causally responsible for the speaker's beliefs (or that fits the speaker's concept), we find a worm $\mathrm{w}$ consisting of all of the slices I-related to $\mathrm{s}$, and the sentence is true iff a slice of $\mathrm{w}$ prior to the time of utterance is tall. According to both theories, the slice s and the worm w are used in exactly the same way. Slice Theory says, "both s and $\mathrm{w}$ are important: $\mathrm{s}$ is the slice causally responsible for the speaker's beliefs, viz. the referent, and $\mathrm{w}$ is the sum of all slices in virtue of which temporally extrinsic predicates about the person are evaluated, what we might call the referent $\left(\mathrm{I}_{\text {person- }}\right.$ ) expanded." Worm Theory says, "both $\mathrm{s}$ and $\mathrm{w}$ are important: $\mathrm{s}$ is the slice causally responsible for the speaker's beliefs, what we might call the referent determiner, and $\mathrm{w}$ is the sum of all slices in virtue of which temporally extrinsic predicates are evaluated, viz. the referent." Since s and w have the same role on both theories, we might wonder on what basis one theory calls $\mathrm{s}$ 'the referent' and the other calls $\mathrm{w}$ 'the referent'. On the face of things, theorists of the two camps are arguing past one another: what Slice Theory means by 'the referent' is what Worm Theory means by 'the referent determiner' and what Worm Theory means by 'the referent' is what Slice Theory means by 'the referent expanded'.

Pressing the point, we can imagine an artificially intelligent robot that goes through the steps mentioned above, retrieving a descriptor for the slice that it saw in the photograph, generating a descriptor for the worm constructed from this slice, and finally asserting "Tom was tall" in order to convey the information that some slice of that worm prior to the time of utterance is tall. Which of Slice Theory or Worm Theory better captures the robot's semantics? It seems there is nothing about the robot, nor any other fact about the world, that determines this. For that matter, what fact can we even imagine that could differentiate the two views? And, more to the point, it is hard to see how human cognitive processes could differ from the robot's such that one theory correctly captures our semantics and the other does not. Again, it seems that the two theories do not differ in substance, that they differ only in using different expressions to pick out the same relations. ${ }^{40}$

Both Worm Theory and Slice Theory can account for the same puzzles since they generate identical truth conditions and do so by evaluating sentences in the same exact way. No ontological considerations have been offered — and it is difficult to imagine any — that

\footnotetext{
40 The sort of parallelism I am urging is familiar from Quine (see, e.g., Word and Object, Ch. 2). As will soon become apparent, however, my ultimate point is quite anti-Quinean. Far from being parallel, one of the theories of reference, I argue, is self-undermining.
} 
distinguish them, for both endorse the existence of the same slices and worms. ${ }^{41}$ It thus seems that the two theories are in fact the same theory under different guises - that is, the same ontologically as well as semantically! This may strike some as utterly fantastic. After all, doesn't Worm Theory claim that objects are temporally extended worms, and doesn't Slice Theory claim that objects are momentary slices of these worms? Don't they therefore disagree on many counts? Not necessarily.

\section{Confusing Languages}

One objection to Slice Theory we've already examined is the claim that according to Slice Theory Ted does not persist, which conflicts with common sense since he clearly does persist. Applying the semantics, though, we found that "Ted persists" is true. Thus, Slice Theory does say that Ted persists and does agree with common sense. "But surely," one might reply, "the core idea of Slice Theory is that ordinary objects are slices and slices exist only at single times. Ergo, the theory says that Ted does not persist." It seems the theory says one thing and the semantics endorsed by the theory say the opposite. One can avoid this inconsistency, I argue, only by taking the claims characterizing Slice Theory to mean something quite different than what they seem to mean. That is, either the Slice Theorist's claim that ordinary objects are time slices is not a claim of English, in which case the Slice Theorist only appears to make a radical claim, or, if we instead take her claims at face value, then the theory contradicts itself.

The main piece of evidence has just been presented. The semantics say that "Ted persists" is true in English and "Ted does not persist" is false. ${ }^{42}$ And, disquoting, this means that according to the theory Ted persists. Yet, as mentioned, the whole idea behind Slice Theory, which in fact is presupposed by the truth conditions given in the metalanguage, is that Ted and all other ordinary material objects are slices that do not persist. This already suggests that the theory is either inconsistent or incorrectly described.

In fact, the case is even stronger. A statement saying that $\mathrm{S}$ is at some time $\mathrm{t}$ is, according to Slice Theory, to be taken as saying that $\mathrm{S}$ bears the appropriate temporal counterpart relation to a slice at that is . I will assume, for now, that all temporal predications - i.e., predications involving something being a certain way at some time - are to be analyzed in a consistent manner. "Goliath is tall at $\mathrm{t}$ " is true iff Goliath has a statue counterpart that exists at $\mathrm{t}$ and is tall. "The puppy is drooling at $\mathrm{t}$ " is true iff the puppy has a dog counterpart that exists at $\mathrm{t}$ and is drooling. And, for consistency, "Shanna exists at t" is true iff Shanna has a person

\footnotetext{
41 As David Christensen has pointed out to me (in conversation) and as Hawley notes (How Things Persist, p. 52), however, a Slice Theorist could remain neutral with respect to the existence of time worms. Even if one denies the existence of arbitrary sums, though, the worms in question are sums of intimately related slices rather than arbitrary sums. It is thus difficult to see the motivation, at least for the four-dimensionalist, for embracing the existence of spatially spread out objects but not temporally spread out objects. Nonetheless, this could provide a metaphysical difference between the two theories. In order to remove this one potential difference, one might construct a Worm Theory that avoids commitment to worms by saying that names of ordinary objects are, in fact, referring to pluralities, viz., collections of slices. See footnote 49 for more on this potential ontological difference.

42 For simplicity's sake, let's treat "Ted persists" as synonymous with "Ted exists at multiple times" (in fact persistence requires existing at all times throughout a continuum). Nonetheless, we need to be careful how we analyze this latter statement. We cannot simply say "Ted exists at multiple times" is true iff a slice I-related to Ted exists at multiple times, just as we cannot say "Ted is growing at $t$ " is true iff a slice I-related to Ted existing at $t$ is growing. These are temporally extrinsic predicates, i.e., predicates that are true of a referent in virtue of how the referent is (or how its counterparts are) at times not limited to the target time. These are to be analyzed in terms of multiple slices. Thus, we want the more natural, “Ted exists at multiple times" is true iff $(\exists t)(\exists t$ ') $(t \neq t$ ' \& Ted is Irelated to a slice existing at $\mathrm{t} \&$ Ted is I-related to a slice existing at t').
} 
counterpart that exists at $t$ and exists. But this means we are giving an analysis of the object language predicate 'exists at $t$ ' in terms of the metalanguage predicate 'exists at $t$ '! Moreover, it is clear that the two predicates mean different things, for the object language predicate 'exists at $\mathrm{t}$ ' is true of the referent iff the spatio-temporal boundary of a slice bearing the appropriate counterpart relation to the referent overlaps $t$, whereas the metalanguage predicate 'exists at $t$ ' is true of the referent iff the spatio-temporal boundary of the referent itself overlaps $t$. What could be clearer evidence that homonymous terms of the two languages are different!

To put the objection in perspective, notice that the problem plagues temporal counterpart theory but not modal counterpart theory. A common complaint against modal counterpart theory is that when we talk about the possibility of Humphrey winning the election what we are talking about is Humphrey himself, not the goings-on (at some other world) of some other individual, as counterpart theorists would have it. But, comes the reply, common sense only says that when we're talking about the possibility of Humphrey winning we're talking about Humphrey himself and what he possibly does, which the counterpart theory endorses, since possibly doing something is analyzed in terms of a modal counterpart doing that thing. The objection that the theory mistakes some fact about someone other than Humphrey for a fact about Humphrey himself would be well placed only if common sense had something to say about what Humphrey and distinct possible individuals do at other possible worlds, which it doesn't since talk about other worlds is not a part of common sense but a part of the theoretical posits of the theory. With Slice Theory, in contrast, common sense says that what's going on at noon on January 1, 1980 is Ted himself playing basketball, which directly contradicts what the theory says. Whether a person exists at other worlds is a theoretical dispute, whereas whether she exists at other times is a matter of common sense.

Let's call the Worm Theory metalanguage Wormese and the Slice Theory metalanguage Slicese. Both theories say they are giving truth conditions for English, so in both cases we'll take English to be the object language. I have argued so far that if we are to avoid inconsistency, Slicese terms must mean something different than homonymous terms in English. ${ }^{43}$ Moreover, the evidence that shows that Slicese has this problem does not, mutatis mutandis, show that Wormese does. The problem has been that Slice Theory makes claims like, "Ted is a momentary slice", "Ted' refers to a slice", and "Slices do not persist", which conflict with ordinary claims of English that the theory itself takes great pains to accommodate.

An advocate of Slice Theory will likely protest that Slicese is English, that the claims of the theory are to be understood as meaning exactly what they seem to mean. But is there any reasonable way for Slice Theory to maintain this? Let's consider some possible lines of defense.

Let's first consider a version of Slice Theory that consistently claims that objects do not persist. That is, let's consider a theory that does not use temporal counterparts when giving the semantics of "persists'. Instead of saying that "Tom persists" is true iff Tom is I-related to slices that exist at multiple times, it will say something like that "Tom persists" is true iff Tom exists at multiple times (where 'existing at' is not, in turn, cashed out using counterparts). I will assume that this theory will still try to maintain the intuitive truth values of most sentences by explaining most tensed predications in terms of extrinsic relations to other slices - without this basic story, almost all everyday tensed predications we take to be true would, according to our theory, in fact be false. So the Slice Theory we are considering now would say that "Tom was born sixty years

\footnotetext{
43 Both Slicese and Wormese are metalanguages used to analyze tensed predications and thus both employ only tenseless predications. In this sense, both metalanguages differ from English in a way that is unproblematic. The worry, however, is that with Slice Theory the tenseless statements of the metalanguage mean something different than those of the object language.
} 
ago", "Tom rode horses when he was young", and the like are true. However, because this theory denies that objects persist, this means that all of the normal entailments based upon what it is to persist must now be denied. This version of Slice Theory would agree that Tom was born sixty years ago and still lives today but would deny that Tom persists; it would agree that my bicycle broke a year ago and now sits in the basement rusting but would deny that my bicycle persists. That is, the theory would systematically contradict common sense both regarding the vast majority of inferences we take to hold in virtue of the meaning of 'persists' and regarding the truth of most statements about which things persist. In short, it looks like we have every reason to believe that the version of Slice Theory we are considering means something else by 'persistence' than what we mean. In short, denying that objects persist while maintaining their other intuitive temporal properties is not a realistic option. Notice that this conclusion holds whether we interpret "Tom persists" as tensed or tenseless. Of course, we might have wondered from the start why some temporally extrinsic properties, such as having been born sixty years ago or having ridden horses, are to be analyzed in terms of extrinsic relations to other slices while another temporally extrinsic property, viz. persisting, is not to be analyzed in a corresponding fashion.

Slice Theory consists of two interrelated claims: 1) names of ordinary objects refer to slices that only exist at one point in time, and 2) tensed predicates are to be analyzed using counterpart relations the referent bears to slices existing at times determined by the tense. But we have seen a difficulty with this approach. On the one hand, if only some predicates are analyzed using temporal counterparts while others are not, the inevitable outcome is widespread conflict with common sense in two ways. First, because the counterpart analysis compensates for the strange theoretical claims of Slice Theory, sentences using predicates that are not analyzed using counterpart relations will conflict in truth value with common sense. Second, by analyzing some predicates using counterparts and not others, the normal entailments between sentences using the two different sorts of predicates will likewise conflict with common sense. Thus, although we have examined only one example of such conflicts when 'persists' was not given a counterpart-theoretic analysis though other predicates were, it is clear that the same problem generalizes to 'exists at t', 'overlaps t', or any other predicates. On the other hand, if all predicates attributing temporally extrinsic properties are analyzed in the same counterparttheoretic manner, then we cannot reconcile the statements judged true by the semantics, such as that Tom persists, and the statements used to explain the theory, such as that ordinary objects are momentary slices.

The Slice Theorist, however, might insist that we can satisfy these two seemingly conflicting claims of Slice Theory using a uniform analysis of predicates as long as we keep in mind that the counterpart analysis is relative to a sort. That is, we can talk about persons and say that Tom does persist and yet later talk about slices and say that the slice to which 'Tom' refers does not persist, for the referent of 'Tom' is $\mathrm{I}_{\text {person-related to slices that exist at other times }}$ but is not $\mathrm{I}_{\text {slice}}$-related to a slice that exists at another time.

The problem with this response is that the analysis of predicates that are true of referents in virtue of sort-relative temporal counterpart relations requires a prior notion of existence that is not relative to a sort and does not hold in virtue of temporal counterparts. As Lepore and Ludwig note, in order to analyze a relativized term, one must use a metalanguage that is not similarly relativized; only in this way can the analysis make explicit that the term is relativized and make explicit how it is relativized. ${ }^{44}$ If the Slice Theorist wants to say that the person Tom exists at other times yet the slice to which 'Tom' refers does not, and if she makes sense of this

44 “Outline of a Truth Conditional Semantics for Tense," $\$ 2$. 
by analyzing 'exists at other times' in terms of whether or not the referent bears some sortrelative counterpart relation to slices that exist at other times, we can only understand this analysis by taking the phrase 'exist at other times' as it appears in the analysans as not sortrelative. In fact, the non-relativized notion is already required insofar as the theory presupposes a grip on the distinction between a slice, i.e., something that exists only at a moment, and a worm, i.e., something that exists at multiple times. That is, we all think worms are, and slices are not, things that exist at multiple times, but this distinction requires an antecedent understanding of existence that is not in terms of counterpart relations the object bears to things that exist at other times. Thus, whether or not there is some other notion of existence that is relativized and holds in virtue of temporal counterparts, Slice Theorists must also employ this more basic, unrelativized notion of existence. But this means trouble, for if we do employ an unrelativized sense of 'exists' and can distinguish it from the relativized sense, it seems clear that the sense we employ in everyday English is the unrelativized sense. For when we think that Tom exists at various times and ask ourselves what is required for this, we see that what we mean by 'exists' in such a thought is not something that holds in virtue of the referent of 'Tom' bearing some relation to something else. Thus, because understanding the temporal counterpart relation relies upon understanding an unrelativized sense of 'exists', and because we have intuitions about what exists in this sense, all of the conflicts that the Slice Theorist hoped to avoid by appealing to a relativization of our predicates come back in full force.

Some sort of relativization to a sort must be part of any story. Worm Theory, e.g., will appeal to a shift in context to explain why both of the following statements can be true and yet there be no conflict: "This [pointing towards a statue/lump on the mantle] was in the garage all last week," and, later, "This [pointing again towards the statue/lump] was created just this morning." The Worm Theorist says 'this' picks out different referents in different contexts, whereas the Slice Theorist says 'this' invokes different counterpart relations. Worm Theory can therefore accommodate the two different contexts, what we might call the two different things we mean by 'this', and the Slice Theorist has a parallel explanation of the two contexts. But the problem is that the Slice Theorist relies upon a mechanism according to which ordinary terms refer to things that don't - i.e., don't really — exist for more than a moment, and it is this extra commitment that Slice Theory alone embraces.

The thoroughgoing parallel between the truth conditions for Worm Theory and those for Slice Theory that we have discovered is the secret to Slice Theory's success, for only so can it save common sense as well as Worm Theory does. But this parallel is also its undoing, for it guarantees that the only claims it makes that sound controversial are claims in Slicese, claims that - if they are taken to be claims of English — are judged false by the truth conditions of the theory itself. ${ }^{45}$

\section{Conclusion}

There is a striking parallel between Slice Theory, once patched up, and Worm Theory. Slice Theory and Worm Theory give different accounts of which individuals a term refers to and which individuals a predicate is true of. However, the differences compensate for each other such that both accounts require the same conditions for a sentence to be true. This, presumably, explains why so many have been tempted by Slice Theory. Both theories go through the exact

\footnotetext{
${ }^{45}$ Quine used compensating differences to argue that two semantic theories can be empirically adequate and, hence, correct. I, in contrast, am arguing that because of Slice Theory's compensating differences, which allow this radical theory to preserve common sense, the theory undermines itself, endorsing claims that fly in the face of the theory itself.
} 
same process to determine the truth of a sentence, using the same slices and the same worms in exactly the same way, their only difference being which of these things used along the way they call the 'referent'. Compare the physicist who endorses a theory the same in all ways to current physics except that where 'electron' appears in the current theory 'proton' appears in hers and where 'electron' appears in hers 'proton' appears in the current theory. We would say that she has not discovered a new theory but has chanced upon the current theory in different terms. Either we would interpret her claim, "Electrons have positive charge!" as meaning that protons have positive charge or, if she denied this interpretation, we would simply dismiss her claim. Our judgment of Slice Theory should be the same.

It is not simply that Slice Theory conflicts with common sense. That is to be expected from a theory that says that ordinary objects are time slices. Rather, the problem is that the theory, if consistently applied, generates truth conditions that themselves judge the claims of the theory to be false. Only if the theory is applied inconsistently will it escape this internal conflict, but then the result is massive systematic disagreement with common sense of just the sort that suggests that the theory is incorrectly analyzing our terms. Like the physicist's theory, if we interpret Slice Theory charitably, it says nothing new or controversial, yet if we interpret it literally, it is false.

Slice Theory consists of a radical metaphysics of everyday objects conjoined with a semantics of tense that is intended to reconcile those metaphysical claims with the claims of common sense. The semantic reconciliation, however, undermines the metaphysics. This is, in hindsight, to be expected since in order to accommodate common sense, the semantic theory must differ from the standard semantics in exactly those ways that would compensate for the non-standard metaphysical claims. The inconsistency of Slice Theory is of interest insofar as it tells us which of the two versions of temporal parts theory, if either, is correct. It seems, however, that this inconsistency does not stem from any of the particulars of Slice Theory but is a consequence simply of semantic accommodation, which in fact is commonplace. For example, van Inwagen claims that chairs don't exist but that everyday claims such as "There are four chairs at the table" are nonetheless true in virtue of chair-wise arrangements of atoms. ${ }^{46}$ Likewise, Lewis tells us that there are at least two objects on the mantle, a statue and a piece of copper, but it is nonetheless appropriate to say that there is only one. ${ }^{47}$ Semantic accommodation is ubiquitous, yet it seems that the same inconsistency lurks beneath all such cases. ${ }^{48}$ Semantic

\footnotetext{
${ }^{46}$ See, e.g., Material Beings.

${ }^{47}$ See, e.g., On the Plurality of Worlds, pp. 218-9 and "Survival and Identity".

${ }^{48}$ As a brief sketch of how we might uncover inconsistencies in cases where semantic accommodation is not at first apparent, consider the account Jubien offers in "Thinking about Things". According to Jubien, the only physical things that exist are quantities of matter - i.e., things that have their parts essentially. A statement about a familiar kind of thing, such as a statue, is in fact a statement about the thing that currently is the statue as well as about the property of being the statue. Thus, to say that the statue could not have been cubical is not to say that that very thing (the quantity of matter) could not have been cubical but rather "that some physical thing has the property of being the statue, and that that property is incompatible with being cubical" (p. 7). Rather than considering modal properties, let's move to the simpler case of temporal properties. Presumably, a similar story will apply: statements saying that the statue was at location $\mathrm{L}$ at time $\mathrm{t}$ are to be understood as saying that some physical object at $\mathrm{L}$ at $\mathrm{t}$ has the property of being the statue. Thus, "The person here right now was at $\mathrm{L}$ at $\mathrm{t}$ " can be true even though there is nothing here now that also was at $\mathrm{L}$ at $\mathrm{t}$. But according to common sense, from "The person here right now was at $\mathrm{L}$ at $\mathrm{t}$ " we can infer the following series of claims: "Some person here right now was at $\mathrm{L}$ at $\mathrm{t}$ "; "There is some person here right now that was at $\mathrm{L}$ at $\mathrm{t}$ "; "There is something here right now that was at $\mathrm{L}$ at $\mathrm{t}$ "; "Something exists here right now that was at $\mathrm{L}$ at $\mathrm{t}$ ". If the account were to deny the inference from one to the next, it would conflict with common sense both in denying claims that we take to be true and in denying inferences that seem to be trivial. The
} 
accommodation is so popular, though, because the plausibility of a metaphysical theory is diminished to the extent that it conflicts with common sense and that conflict cannot be explained on grounds that are independently motivated. We therefore seem to have grounds for a quite general anti-metaphysical worry! Of course, each metaphysical theory together with its accompanying semantic theory has its own distinctive elements, and these might well preclude the sort of argument given here, so progress must be made by looking at the details of each case. ${ }^{49}$ But it is a sign of the promise of the approach that it shows us why Slice Theory, despite

net result is a systematic disagreement with common sense of just the sort indicating that the account has misinterpreted what we mean by our terms. The account could instead follow the progression to the end and say that the final statement is true iff there is some physical thing here now and some possibly distinct physical thing at L at $\mathrm{t}$, both of which have the property of being the statue. In this case we would fully accommodate everyday talk. But then our semantic theory would endorse claims that the metaphysical theory is denying. Whenever common sense has it that an object persists through a change in its constituent matter, then we have a case where Jubien's semantic theory would endorse the claim, "Something exists here right now that was at L at t," even though his metaphysical theory would deny it. Much more would need to be said to mount a forceful attack on Jubien's account. My hope is instead merely to sketch how the problem of semantic accommodation threatens to apply quite widely indeed.

${ }^{49}$ Although I intend to show only that there is some plausibility to the idea that the threat of an inconsistency generalizes, I will briefly respond to one objection. One might complain that the inconsistency is not to be found with most metaphysical theories, for the debate between Worm Theorist and Slice Theorist is merely a semantic issue about what our terms refer to, while most issues of concern to metaphysicians, such as those of van Inwagen and Lewis, are more fundamental questions over what exists. But, say I, the sorts of semantic issues we are investigating just are metaphysical issues examined through semantic ascent. The metaphysical issue about the nature of everyday objects - whether they are temporally extended or not — has been recast as the issue of whether our terms for everyday objects refer to worms, which are extended, or slices, which aren't. The issue of whether chairs exist would likewise be recast as the issue of whether the word 'chair' is to be treated as a singular referring term or is to be given some more complex analysis, e.g. one employing plural quantifiers over atoms.

To press the point, imagine a version of Slice Theory that doesn't agree with Worm Theory about what exists but instead denies the existence of worms. One might think that the defense of Worm Theory given in this paper would be inadequate as a response to such an opponent since an adequate defense would also have to establish that worms exist, i.e., something in addition to what has been offered here. One could insist, however, that the two competing theories would still have identical truth conditions, as long as these truth conditions abstract away from any talk of worms. That is, under both theories, "Tom was tall" is true at $t$ iff there is a person slice s that is causally responsible for the speaker's beliefs (or that fits the speaker's concept), there is a series of slices, each of which is Irelated to $\mathrm{s}$, and a slice of this series existing prior to $t$ is tall. Thus, rather than couching the truth conditions in terms of there being a certain worm, the Worm Theorist, like the Slice Theorist, could couch them in terms of there being a certain series of slices. One who thinks the existence of worms is something independent of the series of slices composing it would demur, insisting that if Worm Theory is correct, then the truth of statements about persons requires not only that there be various slices that have certain properties and that are related in certain ways but also that there be worms, and in particular worms composed of those slices. However, one who thinks a worm just is a series of slices would find the defense already given all one could — or should! — provide. As some have already protested in response to those who deny chairs and yet concede that there is matter arranged chair-wise, "But that's all I mean by 'chair'!" (Cf. Merricks, “"No Statues"”)

Consider, in contrast, the view on which the existence of a chair is a matter not entirely settled by the existence of a certain collection of atoms arranged chair-wise that is commonly said to constitute that chair. Whatever additional thing there is that makes those atoms compose a chair could, on this view, cease to obtain even as I continue to sit upon that chair-wise arrangement of atoms. Simplicity surely counts against such metaphysical extras. (cf. Reasons and Persons, §81) Stronger yet, it seems to me that even if there does exist some metaphysical extra attached in some way to that collection of atoms, our concept of a chair would be satisfied not by that extra or even by the chairwise arrangement of atoms together with that extra; rather, it would be satisfied solely by the chair-wise arrangement of atoms. With the chair-wise arrangement of atoms we would have that which we see as a chair, that which supports us as a chair, that which is serving its intended purpose, etc. Thus, I conclude, we can spell out the 
its growing popularity, cannot deliver both the radical metaphysic it advertises and the reconciliation with common sense that is necessary for us to swallow it. ${ }^{50}$

truth conditions for sentences about chairs without appeal to any such metaphysical extras. Those who see a sharp divide between the semantics for 'exists' and the semantics for other predicates (see, e.g., the 'Introduction' to Sider's Four-Dimensionalism) will probably not be persuaded, but I hope here merely to show that the denial of such metaphysical extras is not implausible and, hence, that it is reasonable to think that the problem with semantic accommodation is not specific to Slice Theory but threatens other radical metaphysical theories as well.

${ }^{50}$ I wish to thank David Christensen, Troy Cross, Cian Dorr, Kit Fine, Hilary Kornblith, Tim Maudlin, Brian McLaughlin, Derk Pereboom, Jeremy Pierce, Ted Sider, Ernest Sosa, and an anonymous referee for many useful comments on various versions of this paper. 


\section{Cited Works}

Armstrong, David. "Reply to Lewis," in Ontology, Causality, and Mind, ed. John Bacon, Keith Campbell, and Lloyd Reinhardt. Cambridge: Cambridge University Press, 1993.

Berkeley, George. A Treatise Concerning the Principles of Human Knowledge, ed. Kenneth Winkler. Indianapolis: Hackett, 1982 (originally published in 1710).

Chisholm, Roderick M. Person and Object: A Metaphysical Study. London: George Allen \& Unwin Ltd., 1976.

Evans, Gareth, "The Causal Theory of Names," Aristotelian Society Supplementary Vol. 47, 1973.

Field, Hartry H. "Theory Change and the Indeterminacy of Reference," Journal of Philosophy 70 (1973), pp. 462-481.

Gibbard, Allan. "Contingent Identity," Journal of Philosophical Logic 4 (1975), pp. 187-221.

Hawley, Katherine. How Things Persist. Oxford: Oxford University Press, 2001.

Hazen, Allen. "Counterpart-Theoretic Semantics for Modal Logic," The Journal of Philosophy 76, 1979, pp. 319-338.

Heller, Mark. "Temporal Parts of Four Dimensional Objects," Philosophical Studies 46 (1984), pp. 323-334.

Igal Kvart, "Divided Reference," Midwest Studies in Philosophy, Vol. XIV, 1989, pp. 140-179.

Johnston, Mark. "Constitution is not Identity," Mind 101 (1992), pp. 89-105. Reprinted in Rea, Material Constitution.

Jubien, Michael. “Thinking about Things,” Philosophical Perspectives 15 (2001), pp. 1-15.

Kvart, Igal. "Divided Reference," Midwest Studies in Philosophy 14 (1989), pp. 140-179.

Lepore, Ernest, and Kirk Ludwig. "Outline of a Truth Conditional Semantics for Tense," forthcoming in Tense, Time and Reference, ed. Q. Smith, New York: Kluwer.

Lewis, David. On the Plurality of Worlds. Oxford: Basil Blackwell, 1986.

Lewis, David. Philosophical Papers, v. 1. New York: Oxford University Press, 1983.

Lewis, David. "Survival and Identity," in The Identities of Persons, ed. Amelie O. Rorty (University of California Press, 1976). Reprinted in Lewis's Philosophical Papers, vol. 1.

Merricks, Trenton. “'No Statues"”, Australasian Journal of Philosophy 78 (2000), pp. 47-52.

Parfit, Derek. Reasons and Persons. Oxford: Oxford University Press, 1984.

Perry, John. "Can the Self Divide?", The Journal of Philosophy 69 (1972), pp. 463-488.

Perry, John. "The Same F," The Philosophical Review 79 (1970), pp. 181-200.

Quine, W. V. "Ontological Relativity," in Ontological Relativity and Other Essays. New York: Columbia University Press, 1969.

Quine, W. V. Word and Object. Cambridge, Mass.: MIT Press, 1960.

Rea, Michael C., ed. Material Constitution: A Reader. New York: Rowman \& Littlefield, 1997.

Rea, Michael C. "Sameness without Identity: An Aristotelian Solution to the Problem of Material Constitution," Ratio XI (1998), pp. 316-328.

Robinson, Denis. "Can Amoebae Divide Without Multiplying?", Australasian Journal of Philosophy 63 (1985), pp. 299-319.

Sider, Theodore. "All the World's a Stage," Australasian Journal of Philosophy 74 (1996), pp. 433-453.

Sider, Theodore. Four-Dimensionalism: An Ontology of Persistence and Time. Oxford: Clarendon Press, 2001.

Simons, Peter M. Parts: A Study in Ontology. Oxford: Clarendon Press, 1987. 
Thomson, Judith Jarvis. “The Statue and the Clay,” Nô̂s 32 (1998), pp. 149-173.

van Inwagen, Peter. Material Beings. Ithaca: Cornell University Press, 1990.

White, Nicholas. "Identity, Modal Individuation, and Matter in Aristotle," Midwest Studies in Philosophy XI (1986), pp. 475-494.

Wiggins, David. Sameness and Substance. Cambridge, Massachusetts: Harvard University Press, 1980. 